\title{
Hava Trafik Yönetimi Araștırma Alanlarının Sınıflandırılması
}

\author{
Kübra CELIKK ${ }^{1}$, Haluk EREN²*
}

${ }^{1,2}$ Hava Trafik Kontrol Bölümü, Sivil Havacılık Yüksekokulu, Fırat Üniversitesi, Elazı̆̆g, Türkiye

${ }^{1}$ k.celik@ firat.edu.tr, *2heren@ firat.edu.tr

Öz: Hava trafik yönetiminde son yıllarda öne çıkan araștırma alanları hem geleneksel uygulama konularını kapsamakta hem de bilim ve teknolojideki yeni gelişmelerle beslenmektedir. Bu hızlı değişimi takip edebilmek için güncel Hava Trafik Yönetimi (HTY) konularının önem derecesine göre bilinmesi ve sınıflandırılması gerekmektedir. Bu çalışmada günümüzde dikkat çeken ve gelecekte önem kazanması muhtemel HTY araştırma konularının; hava trafik otoritelerindeki karşılıkları da dikkate alınarak bir sınıflandırma yapılmıştır. Araştırma konuları 7 ana başlığa ve ilgili alt başlıklara ayrılarak sınıflandırılmıştır. Operasyonel Sistemler, Haberleşme ve Seyrüsefer Sistemleri, Performans ve Verimlilik, Veri Analizleri, Emniyet ve Güvenlik, Hukuk ve Politikalar ve Yeni Teknolojiler ana başlıkları incelenmiştir. Bu alanda daha hızlı gelişen konulardaki yeni araştırma alanları ile ilgili kısa örnekler verilmiştir. Bu sınıflandırmanın gelecekteki HTY problemlerine 1şık tutabileceği düşünülmektedir. Sonuçta bu çalışmada dünyada hava trafik alanındaki mevcut araştırmalar hakkında değerlendirmeler verilerek bu alanda çalışmak isteyen araştırmacılara bir ufuk açılması hedeflenmektedir.

Anahtar kelimeler: Hava trafik yönetimi, hava trafik kontrol, hava ulaşımı, HTY yeni teknolojiler

\section{Classification of Air Traffic Management Research Areas}

\begin{abstract}
In recent years, research areas in air traffic management cover both traditional application areas and new developments in science and technology. In order to follow this rapid change, current Air Traffic Management (ATM) areas need to be classified according to their significance. In this study, a classification is made considering the air traffic authorities. The research areas are classified into seven main topics. Operational Systems, Communication and Navigation Systems, Performance and Efficiency, Data Analysis, Safety and Security, Law and Policies, and New Technologies are examined. Some examples are given about the fast developing research areas. This classification could help to find solutions to future ATM problems. As a result, in this study, it is aimed to make a guideline for the researchers who want to work in air traffic management field.
\end{abstract}

Key words: Air traffic management, air traffic control, air transport, ATM new technologies

\section{Giriş}

Hava Trafik Yönetimi (HTY) uçağın ilk kalkışından, hava sahasındaki intikali ve inişine kadar yardımcı olmak üzere kurulu tüm sistemlere verilen genel bir isimdir. Hava ulaştırma ve trafik sistemleri, içerisinde pek çok farklı iç dinamikler barındıran ve homojen olmayan karmaşık bir sistemdir. Uluslararası Sivil Havacılık Organizasyonu (ICAO) [1], Avrupa Hava Seyrüsefer Güvenliği Örgütü (EUROCONTROL) [2], Avrupa Havacılık Emniyeti Ajansı (EASA) [3] ve M. Cavcar'ın yaptığı Sivil Havacılık Faaliyetlerinin sınıflandırılmasına göre Hava Seyrüsefer Hizmetleri (Air Navigation Services) üç ana konu başlığı ile ilgilenmektedir. HTY ise bu başlıklardan biridir [4]. Şekil 1'de HTY'nin Sivil Havacılık faaliyetleri içerisindeki yeri ve HTY bileşenleri gösterilmiştir.

Bir uçağın emniyetli uçuşundan yalnızca o uçağın pilotu sorumlu iken hava sahalarında ve hava alanları üzerinde hareket eden tüm uçakların birbirine göre emniyetli uçuşundan HTY sistemi sorumludur. Uçuş emniyetini temin eden bu hizmet ülkelerin hava seyrüsefer hizmet sağlayıcıları tarafından verilir.

Türkiye'de bu görev Devlet Hava Meydanları İşletmesi tarafından sağlanmaktadır. Çok sayıda hava aracına en emniyetli, en verimli ve en ekonomik biçimde hizmet verilmesi hava trafik hizmetinin amacı olduğuna göre bu unsurlar arasındaki uzlaştırıcı çözümü Hava Trafik Yönetimi (HTY) (Air Traffic Management-ATM) sağlar [4].

Gerçekte HTY ile a) Hava Trafik Hizmetleri, b) Hava Sahası Yönetimi, c) Hava Trafik Akış ve Kapasite Yönetimi'ni içeren geniş çapta bir yönetimden söz edilmektedir. Şekil 1'de HTY'nin alt bileşenleri şematize edilmiştir [4].

\footnotetext{
${ }^{*}$ Sorumlu yazar: heren@ firat.edu.tr. Yazarların ORCID Numarası: ${ }^{1}$ 0000-0002-0878-7085, ${ }^{2}$ 0000-0002-4615-5783
} 

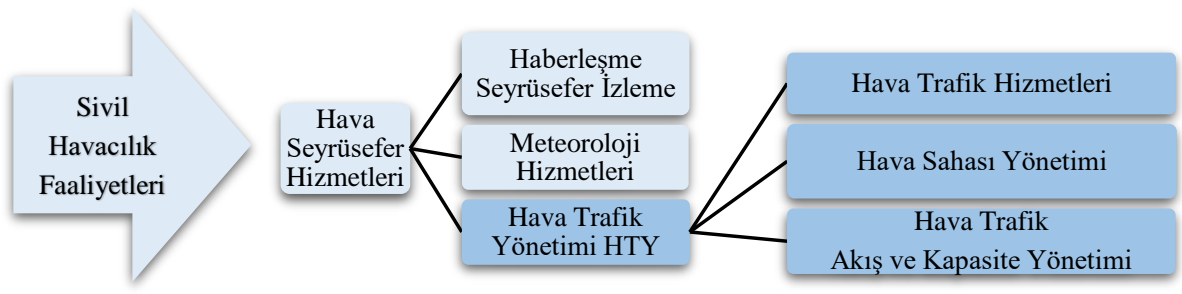

Şekil 1. (a) Hava Trafik Yönetiminin (HTY)'nin Sivil Havacılık faaliyetleri içerisindeki yeri ve HTY bileşenleri [4]

Hava trafiği dünya çapında her geçen gün büyük bir hızla artmaktadır. Şekil 2 (a)'daki grafikte ICAO 2017 dünya hava taşımacıllk verilerine göre 2008-2017 arası yıllık kilometre başına yolcu geliri (RPK) değişimi verilmiştir. Bu veriye göre RPK'da \%7.9 bir atış görülmektedir [5]. RPK'daki bu artış hava trafiğindeki artış ile ilişkilidir. Bu da bize HTY uygulamalarının yıllar içinde artarak bir gelişim gösterdiğini söylemektedir. Bir diğer önemli durum hava trafiğindeki çeşitliliğin yıllara göre farklılaşmasıdır. Örneğin son yıllarda İnsansız Hava Araçlarının (IHA) yaygınlaşması ile İHA trafik yönetimi kavramı doğmuştur. Amerikan Ulusal Havacılık ve Uzay Dairesi (NASA) tarafından 2015 'te İHA trafik yönetimi sisteminin geliştirilmesine çalışılmış ve 2019'da saha testlerine başlanmıştır. Şekil 2 (b)'de İHA'lar için alçak irtifa, sivil uçuş sahası şematiği görülmektedir [6].
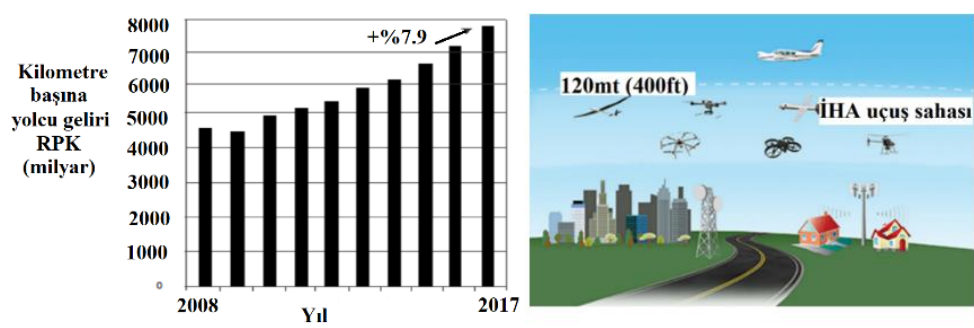

Şekil 2. (a) Hava trafiğindeki artış grafiği ve (b) İHA sivil uçuş sahası şematiği [5,6].

Hava taşımacılığındaki bu hızlı gelişim ve değişim hava trafik kontrolünün önemini arttırmıştır. Hava trafik kontrolörleri tarafindan verilen hizmetler daha karmaşık bir hale gelmiştir. Bunun sonucu olarak yeni hizmetler, yeni tanımlar ve yeni bir terminoloji yaratılmıştır. Ulusal olarak hangi aşamada durduğumuza bakarsak eğer; Türkiye Bilimsel ve Teknolojik Araştırma Kurumu (TÜBİTAK) Bilişim ve Bilgi Güvenliği İleri Teknolojiler Araştırma Merkezi (BİLGEM) bünyesinde sivil havacılık uygulamalarına yönelik ulusal yazılımlar geliştirilmektedir. HTY alanı ile ilgi bu yazılımlardan bazıları; Hava Aracı Takip Sistemi, ATC Kule ve Radar Simülatörü, Hava Trafik Kontrolörü Seçme Yazılımıdır [7]. Ulusal havaalanlarında, dış taşıma, iç taşıma, ekolojik çevre, enerji vs. konularında dünya gündeminin takip edilmesi yerinde olacaktır. Bu sebeple HTY sistem gereksinimleri sürdürülebilir yaklaşımlar dikkate alınarak optimize edilmeye çalışılmaktadır.

\subsection{Problem tanımı}

Son yıllarda havacılığın gelişmesi ile HTY'de pek çok bilginin dikkate alınması gereksinimi doğmuş ve mevcut konular içerisinden bazıları daha fazla ön plana çıkmıştır. Dolayısıyla HTY alanında çalışacak araştırmacıların yeni gelişmeleri yakından takip etmeleri gerekmektedir. Böylece gelecekte çok daha büyük hacimlere ulaşabileceği tahmin edilen hava trafiğinde ortaya çıacak problemler için erken çözüm önerileri ortaya çıkabilecektir. Bu çözümlere ulaşabilmek için güncel HTY konularının önem derecesine göre bilinmesi ve sinıflandırılması gerekmektedir.

\section{2. Önerilen yaklaşım ve metodoloji}

HTY'deki pek çok kural ve bunların uygulanması bağlı bulunulan uluslararası otoritelerin dışında düşünülemez. Dolayısıyla araştırma çalışmaları bu otoritelere öneri şeklinde sunulabilir ve uygulamalar içerisinde yer bulabilir. Gerek hava trafik kontrolörleri gerekse pilot ve diğer personelin uyumlu bir şekilde çalışarak maksimum verim ve güvenlik gibi konularda optimizasyona ulaşabilmeleri için araştırmacıların kesintisiz desteğine ihtiyaçları bulunmaktadır. Bu anlamda araştırmacıların tamamıyla havacılık kurallarından bağımsız 
hareket edebilmeleri düşünülemez. Dolayısıyla bu çalışmada günümüzde ve gelecekte ön plana çıkan HTY konularının hava trafik otoritelerindeki karşılıkları da dikkate alınarak bir sınıflandırma yapılacaktır.

Dikkate alınmakta olan sorun, tek bir başlıkta açıklanamayacak kadar büyüktür. Bu nedenle yayında bu tür sistematik için en uygun metodoloji; mevcut HTY sistemindeki araştırma alanlarının sivil havacılık otoritelerindeki karşılıkları dikkate alınarak ana başlıklara ayrılması olarak seçilmiştir. Bu ana başlıklar Uygulama Alanları dikkate alınarak seçilmiştir. Sınıflandırma sistematiğine bakıldığında bu yayında tercih edilen araştırma yöntemi "Bilimsel Araştırmaların Sınıflandırılmasına" göre "Araştırma Modeli Açısından Sınıflandırmaya” girer. Alt başlık olarak "Keşifsel Araştırmalar" ve "Betimsel Araştırmalar" sınıfına girmektedir.

\subsection{Katkılar}

Literatürde var olan çalışmaların çoğunda genellikle vaka ya da sistem esaslı sınıflandırmalar yapıldığ görülmektedir. Dolayısı ile HTY problemlerinin genel resminin anlaşılmasına yönelik katkı konusunda boşluk bulunduğu görülmüştür. Bizim çalışmamız HTY alanındaki sınıflandırmalar sayesinde gelecek dönem olası problemlere değinmektedir. Böylece HTY alanındaki geleneksel çalışmalardan yola çıkarak güncel problem tanımlarına ulaşılmaktadır. Bu çalışma ile hava trafiği alanındaki gelişmelere bilimsel bir bakış kazandırılacaktır. Artık tamamıyla uygulamadan ibaret gibi görünen rutin konuların teorik karşılığının aranması konusunda araştırmacılara kolaylık sağlanmaktadır. Bu amaçla yapılan sınıflandırmalar sayesinde araştırmacılar kuramsal modeller geliştirerek problemlere çözüm arayacaktır. Çalışmamızda verilen perspektif sayesinde gelecekteki HTY problemlerine bütünsel bir bakış getirilerek her bir parçanın diğer bileşenler ile ilişkisinin anlaşılması sağlanacaktır.

\section{4. İlgili çalışmalar}

2000'li yılların başında Avrupa hava sahasının güvenilirliğini arttırmak için yapılan projelerden biri HERA (Human Error in ATM Project) projesidir. Bu projede kazalardaki HTY insan faktörünün etkisini azaltmak için uygulanabilecek çözümler üzerinde durulmuştur. HTY'deki insan faktörü hatalarının sınıflandırılması bu projenin başlangıcında önemli bir dayanak noktası oluşturmuştur [8]. Hava trafik akışının sınıflandırıldığı çalışmalarda Yörünge Kümelenmesi ve Sınıflandırılması (Trajectory Clustering and Classification) [9,10] ve senaryo bazlı yaklaşım [11] metotları literatürde mevcuttur. Hava trafiği yönetimindeki sektörlerin sınıflandırılması ve karmaşıklık seviyelerinin belirlenmesi üzerine bir çalışma Raphael ve arkadaşları tarafından yapılmıștır. Bu çalışmada hava trafik kontrolörlerinin iş yükleri ve sektör yoğunluklarının olası tahminleri yapılmıştır [12]. Fakat bu çalışmalar genel bir sınıflandırmadan uzaktır. Son yıllarda NextGen sisteminin getirdiği yenilikler ile birlikte HTY'de insan faktörlerinin etkisi artmıştır. Özellikle gelecek yıllar için otomasyon kavramının getireceği faydalar ve olası problemler üzerine yapılan sınıflandırma çalışmaları mevcuttur [13]. HTY'de karmaşık ağların sınıflandırıldığı ve olası gelecek öngörülerinin aktarıldığı bir kitap yayınlanmıştır [14]. Ayrıca HTY'de vaka sınıflandırmalarının yapıldığı ve karmaşık ağlar teorisi yaklaşımını benimseyen çalışma da literatürde bulunmaktadır [15]. Hava trafik kontrolörlerinin öngörülemeyen durumlar karşısında uyguladıkları belirsizlik yönetimi yaklaşımının incelendiği bir çalışmada otomasyon için gerekli stratejiler ve gereksinimler tartışılmıştır. Burada kontrolörlerin karşılaştığı vakalardaki belirsizlik rotaları sınıflandırılmaya çalışılmıştır [16]. Yine son yıllarda gündemde olan İnsansız Hava Araçlarının Hava Trafik Yönetimi İHA-HTY (Unmanned Aircraft System Traffic Management (UTM)) kavramı literatürde yer bulmaya başlamış ve bu konuda sınıflandırma yapıllmaya çalışılmaktadır. Sampigethaya ve arkadaşlarının çalışmasındaki sınıflandırma yaklaşımı kapsamlı bir yaklaşımdan uzak olmakla beraber daha çok siber güvenlik üzerine yoğunlaşmıştır [17]. Türkiye'de İHA-HTY ve HTY kavramlarını bir arada incelemeye alan bir sınıflandırma çalışması da bulunmaktadır, bu çalışmada bulanık mantık modellemesi yöntemi ile HTY karar destek sistemi geliştirilmesi üzerinde durulmuştur [18]. Türkiye'de HTY konu başlığında yapılan sınıflandırma çalışmalarıyla ilgili olarak 2015'te Anadolu Üniversitesinde (AÜ) Özbek tarafından yapılan çalışmada HTY'de koordinasyon başlığı incelenmiş ve koordinasyon süreçlerinin betimlenmesi üzerine sınıflandırma çalışması yapılmıştır [19]. Yine AÜ'den başka bir çalışmada Türk hava sahasında meydana gelen ölümcül uçak kazalarına insan faktörleri analiz ve sınıflandırma sisteminin uygulanması üzerine çalışılmıştır [20]. Bu çalışmalar vaka bazlı sınıflandırma örnekleri içermektedir.

Hava Trafik Kontrol (HTK) konusunda son dönem araştırma eğilimleri çok çeşitlidir. Son yıllarda yapılan bazı çalışmalara örnek verilebilir: C. Paşaoğlu tarafından yayınlanan bir doktora tezinde insansız hava araçlarının ulusal hava sahalarına entegrasyonu ve yeni hava trafik yönetimi konsepti için otomatik Hava Trafik Kontrolü (HTK) modellemesi üzerine çalışılmıştır [21]. Bir başka çalışmada Hava trafik akış ve kapasite yönetiminde saha kontrol için toplama noktası yaklaşımı hakkında araştırmalar yapılmıştır [22]. Bu çalışmalar vaka bazlı 
araştırmalardır. Son olarak da HTY araştırma alanlarının kapsamlı sınıflandııılması üzerine bir çalışma 2010 yılında Caves ve arkadaşları tarafından yapılmıştır. Bu çalışmada sistem bazlı HTY problemleri sınıflandırılmakla birlikte gelecek dönem olası problemlere değinilmemiş̧ir [23].

Çalışmamızın ulusal olarak HTY güncel araştırma konularının sınıflandııılması konusunda bir açı̆̆ı dolduracağı düşünülmektedir. Bu yayının farkı son dönem yeniliklerini de içerecek şekilde çok kapsamlı bir sınıflandırma yöntemi sayesinde gelecekteki bilimsel çalışmalara bir öngörü sağlamaktır.

\subsection{Yerleșim düzeni}

İkinci bölümde öncelikle HTY araştırmalarında matematiksel modeller için örnekler verilmiştir. İkinci bölümün alt başlıklarında HTY araştırma alanlarının sınıflandırılması yapılmıştır. Üçüncü bölümde tartışmalar ve yapılan sınıflandırma ile ilgili değerlendirmeler yer almaktadır. Ardından dördüncü bölümde sonuçlar bulunmaktadır.

\section{HTY Araştırmalarında Modelleme}

Bu bölümde modelleme çalışmaları Hava Trafik Yönetimi (HTY) açısından ele alınmaktadır. 90'lı yıllardaki HTY için yapılan modelleme yaklaşımlarında çok seviyeli HTY modeli esas alınmışıtır. Şekil 3'te HTY'nin çok seviyeli sistem modeli verilmiştir. HTY problemleri büyük ölçekli problemler olarak kabul edilmiştir ve HTY problemlerini seviyelere ayırıp, her bir seviyenin kontrol fonksiyonu belirlenmeye çalışılmıştır. Her bir seviye zamana bağımlı bir değişken olarak kabul edilmiştir. Kontrol fonksiyonunun hiyerarşik yapısı; planlama yapısı ve operasyonel işlemler arasında mükemmel bir denge gerektirmektedir [24].

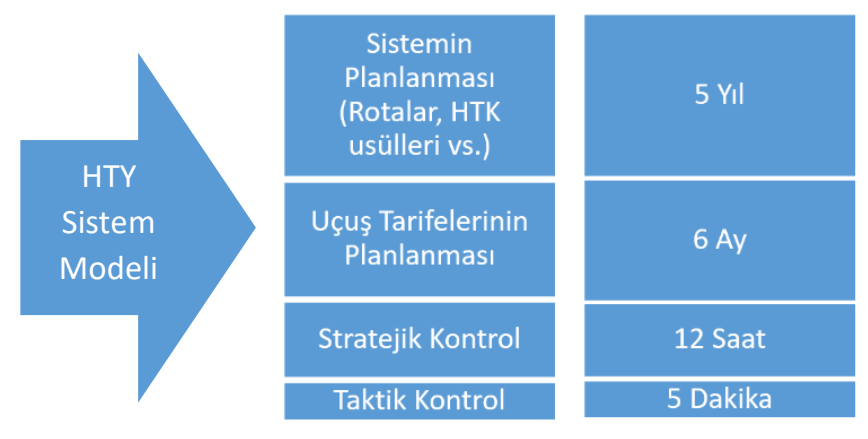

Şekil 3. HTY’nin çok seviyeli sistem modeli [24]

HTK çok seviyeli modelleme çalışmalarında Bianco ve arkadaşları tarafından optimizasyon kullanılmıştır [24]. Ayrıca ilgili yaklaşımın Türkiye hava sahası açısından uygulanabilirliğinin incelenmesi Cavcar ve ekibi tarafından yapılmıştır [25]. Günümüzde HTK konularında yapılan modelleme çalışmalarında Dinamik Yoğunluk (Dynamic Density $(\mathfrak{D D})$ ) yaklaşımı esas alınarak sektör karmaşıklı̆ğ tanımlanması, hesaplanması ve öngörülmesi üzerinde durulmaktadır [26]. Genel $\mathfrak{D D}$ formülü Denklem 1'de verilmiştir [27].

$\mathfrak{D D}=\sum_{i=1}^{n} \Psi_{i} \Gamma \mathcal{C}_{i}+\Gamma \mathfrak{D}+\mathcal{C J}$

Burada; $\Gamma \mathcal{C}$ : trafik karmaşıklık faktörü, $\Psi$ : faktör ağırlığı $i$ : trafik karmaşıklık faktörlerinin sayısı, $\Gamma \mathfrak{D}$ : trafik yoğunluğu, $\mathcal{C J}$ : kontrolör faktörü olarak tanımlanmaktadır. $\mathfrak{D D}$ formülünde $\Gamma \mathfrak{D}$ ve $\Gamma \mathcal{C}$ kullanarak radar ekranlarından okunan veriler sayısallaştırılır. $\mathcal{C J}$ faktörü ise kontrolöre bağımlılığından dolayı şüphesiz sayısallaştııılması en zor değişkendir. Günümüzde HTK modelleme çalışmalarında otomasyon seviyesi yeni bir seviye olarak sisteme dâhil edilmeye çalışılmaktadır [28].

HTY modellemelerinin etkili biçimde yapılabilmeleri için sürdürülebilir bir yaklaşım benimsenebilir. Genel sürdürülebilirlik araştırmalarında ilk olarak Çevresel Etki Değeri'nin bileşenleri modellenmektedir [29]. Sürdürülebilir bir yaklaşım için çevresel etki değerinin sıfır olmasına çalışılmaktadır. Bu değeri etkileyen bileşenler Denklem 2'de verilmiştir.

$I=\rho \times \alpha \times \Gamma$ 
Çevresel Etki Değeri formülüne göre; I:çevresel etki değeri, $\rho$ :nüfus, $\alpha$ :tüketim, $\Gamma$ :teknoloji olarak tanımlanmaktadır. HTY uygulamalarında nüfus bileşeninin $(\rho)$ çevresel etkisi sürekli artmaktadır. Nüfusun artış1 ile beraber ulaşım miktarı artmaktadır. Böylece $(\alpha)$ bileşeninin çevresel etkisi de artmaktadır. $(\alpha)$ ve $(\rho)$ bileşenlerinde meydana gelen bu artışın Teknolojik gelişmelerdeki $(\Gamma)$ çevresel etkilerin azaltılması ile dengelenebileceği düşünülmektedir. Burada yeşil teknolojiler karşımıza çıkmaktadır. HTY açısından yeşil teknolojilerin neler olabileceği üzerine araştırma çalışmaları yapılabilir.

\subsection{HTY araştırma alanlarının sınıflandırılması}

HTY anabilim dalı pek çok araştırma ve uygulama alanını kapsamaktadır. Bu sebeple detaylı bir sınıflandırma gerektirmektedir. Bu çalışmada HTY alanları araştırma modeli açısından 7 ana başlığa sınıflandırılmıştır (Tablo 1). Bu başlıklar; Operasyonel Sistemler, Haberleşme ve Seyrüsefer Sistemleri, Performans ve Verimlilik, Veri Analizleri, Emniyet ve Güvenlik, Hukuk ve Politikalar ve Yeni Teknolojilerdir.

Tablo 1. HTY alanlarının araştırma modeli açısından sınıflandırılması

\begin{tabular}{|c|l|}
\hline \multirow{4}{*}{$\begin{array}{c}\text { Hava Trafik Yönetimi (HTY) Alanlarının } \\
\text { Araştırma Modeli Açısından } \\
\text { Sınıflandırılması }\end{array}$} & HTY'de Operasyonel Sistem Araştırmaları \\
\cline { 2 - 2 } & HTY'de Haberleşme ve Seyrüsefer Sistemi Araştırmaları \\
\cline { 2 - 2 } & HTY'de Performans ve Verimlilik Araştırmaları \\
\cline { 2 - 2 } & HTY'de Veri Analizi Araştırmaları \\
\cline { 2 - 2 } & HTY'de Emniyet ve Güvenlik Araştırmaları \\
\cline { 2 - 2 } & HTY'de Hukuk ve Politika Araştırmaları \\
\cline { 2 - 2 } & HTY'de Yeni Teknolojilerin Araştırmaları \\
\hline
\end{tabular}

\subsubsection{HTY'de operasyonel sistem araștırmaları}

HTY'de operasyonel sistem araştırma alanları arasında; stratejik ve taktik hava sahası yönetimi, hava trafik akış yönetimi, uçuş operasyonları, işlevsel entegrasyon, acil durum planlaması ve kriz yönetimi ile arama kurtarma konularında yapılabilecek çalışmalar bulunur. Bu alanda yapılabilecek araştırmalar çok çeşitlidir. Örneğin Hava Trafik Akış Yönetimi (HTAY) konularında yapılan ulusal bir çalışmada taktik hava trafik akış ve kapasite yönetimi için bir optimizasyon modeli oluşturulmuştur. Çalışmada akışlar planlanırken standart prosedürel ayırma mânialarına dayalı çatışmaların dikkate alınması ve uçakların yerde bekletildiği standart hava trafik akış ve kapasite yönetimi (HTAKY) stratejisinin tercih edilmesi, modelin güncel HTAKY sistemine uyarlanabilir olmasını sağlamıştır. Geliştirilen bu model, özellikle gözetim sistemi olmayan ulusal hava sahalarındaki hava trafik akışlarının planlanması için uygun olabilir [30].

\subsubsection{HTY'de haberleşme ve seyrüsefer sistemi araștırmaları}

HTY'de haberleşme ve seyrüsefer sistemi, simülatörler, radarlar, haberleşme araçları, pilot yer iletişimi, kule cihazları, havacılık haberleşmesi üzerine akademik çalışmaların yapıldığı bir alandır [31]. Tüm bu teknolojik uygulamaları takip etmek ve bu çerçevede frekans koordinasyonunu sağlamak, havacılık meteorolojisi ile ilgili çalışmaları koordine etmek, uygulanmasını sağlamak, havalimanları için aletli alçalma ve standart kalkış/iniş simülasyonlarının yapılması, hava araçları ile uçuş kontrol hizmetinin gerçekleştirilmesi, havacılık simülatörlerinin araştırılması ve gelişmekte olan teknoloji göz önüne alınarak cihaz, sistem ve donanımlar üzerine çalışmaların gerçekleştirilmesini kapsamaktadır [32].

\subsubsection{HTY'de performans ve verimlilik araştırmaları}

HTY'de performans ve verimlilik araştırmaları; toplam sistem performansı, uçak performansı, HTK performansı, yakıt verimliliği ve operasyonların performansı üzerine çeşitli araştırmaların yapılabileceği bir alandır. Örneğin durumsal farkındalık kavramı, üzerinde durulması gereken bir alandır [33]. Kısaca, Durumsal Farkındalık (Situational Awareness-SA), tüm hava sahasının (uçak uçurma, kontrol etme ya da muhafaza etme) analiz edilmesi ve algıların yorumlanmasıdır [34]. SA kavramı HTY'de disiplinler arası araştırmaların yapılabileceği bir alt başlık olarak düşünülebilir. Bu konunun yer trafik uygulamasına bir örnek olarak Eren ve arkadaşlarının çalışmasını verebiliriz. Çalışmada araç sürücüsünün kafa hareketleri takip edilerek sürücü davranışlarının modellenmesi üzerine çıkarımlar yapılmıştır [35]. Aynı yaklaşım HTY konularında da kullanılabilir. Toplam sistem performansı içerisinde önemli başlıklardan biri Emniyet Yönetim Sistemi (EYS) 
uygulamalarıdır. Bu konuda İ. Tunç'un 2018'de yaptığı doktora tezinde emniyet yönetim sistemi uygulamalarının hava trafik kontrol hizmetlerine katkılarının analizi incelenmiştir. Pozitif emniyet kültürünün algısal ve davranışsal boyutunun önemine değinilmiş, toplumumuzda yaygın olarak bulunan suçlama kültürünün etkilerinden bahsedilmiş ve bu durumlara karşı sivil havacıllk sektörünün tüm operasyon birimlerinde uygulanabilecek nitelikte, pozitif emniyet kültürü odaklı yeni EYS modeli önerisi geliştirilmiştir [36].

\subsubsection{HTY'de veri analizi araştırmaları}

HTY'de veri analizi araştırmaları; veri kaynakları ve uçuş izleri, meteoroloji verileri, uçuş planları ve radar verileri hakkında yapılan çalışmaları içermektedir. Örneğin, radarlar her dönüşleri esnasında uçak konumunu ölçerler. Bununla birlikte radarların doğrulukları mesafeye bağlı olarak azalabilir ve radarlar senkronize olmazlar. Değişik doğrulukta radar verilerinin düzensiz ve senkronsuz olarak beslenmesi hava trafik kontrol için sorunlu bir durumdur. Bu tür problemlerin üstesinden gelebilmek için uygun yazılımlar kullanılır. Bu yazılımlar ham radar çizimlerini alır ve daha düzgün uçuş izleri elde edebilmek için radar ölçüm hatasını minimize eder. İzleyiciler pek çok radardan gelen veriyi bir araya getirirler ve radar doğruluğu, uçuş kapasiteleri vs. dikkate alarak iz düşürülen uçak konumlarını hesaplarlar. Genellikle hataları elimine etmek ve olası uçak konumlarına iz düşürmek için Kalman veya Parçacık Filtre gibi filtreler kullanılır. İzleyiciler tarafindan üretilen bu düzgün izler bireysel radar ölçümlerinden daha doğrudur ve uçak performanslarının hesabında kaynak olarak alınabilir. Nerede ve ne zaman uçuşun hava sahasına gireceği, nasıl uçacağı, nerede ve ne zaman çıkacağını hesaplamak üzere uçuş planları ve diğer verileri kullanırlar. Uçuş planı uçağın uçmayı planladığı tüm hava trafik merkezlerine operatör tarafından gönderilir. Ayrıca son olarak meteoroloji verisi, yörüngelerden doğru performansın çıkarılmasında büyük önem taşır.

\subsubsection{HTY'de emniyet ve güvenlik araştırmaları}

HTY'de emniyet ve güvenlik araştırmaları; güvenlik, emniyet, siber saldırılar ve insan faktörü olarak çalışılabilir. Güvenlik ve emniyet alanının kapsadığı konular şunlardır: Havacılık emniyeti ve insan faktörleri, veri analizi, havaalanları, hava sahası ve hava trafik kontrol sistemleri genel koordinasyonuna hâkimiyet, meteoroloji ve çevre konularına hâkimiyet, hava yolu taşımacılığı yönetimi, hava trafik sisteminde emniyet yönetimi. Kulesi olmayan hava alanlarının yakınlarında pek çok çarpışma yaşanmıştır. Bu tür durumlarda trafik örüntüsünde uçak davranışına ilişkin doğru bir modele ihtiyaç duyulmaktadır. Özellikle kayıtlı radar verilerinden trafik örüntü modellerini çıkaran yaklaşımlar mevcuttur. Bu çalışmalarda simülatör verileriyle daha başarılı sonuçlar alınmakla birlikte, gerçek dünya verilerinde gürültüler sebebiyle bir miktar daha efor göstermek gerekmektedir. Siber saldırılar açısından bakılırsa farklı uçuş aşamaları esnasında hava trafik haberleşme tarafindan kullanılan pek çok kablosuz teknoloji mevcuttur. Kavramsal olarak değerlendirildiğinde bunların tamamı güvenli olmayıp güvenlik bunların üretim aşamalarının bir parçası değildir. Son zamanlarda bu tür açıklar araştırmacıların ve siber korsanların ilgi odağı olmuştur. Bununla birlikte, bu tür faaliyetler henüz havacılık içerisinde yaygınlaşma firsatı bulamamıştır. Aynı zamanda, güvenlikle ilgilenen camianın yeterli bir havacılık bilgisi oluşmamıştır. Ayrıca askeri ve sivil uygulamalar açısından ulusal yazılımların gereksinimi siber güvenlik açısından önemlidir. İnsan faktörü açısından güvenlik alanında hava trafik kontrolörlerinin can ve mal kaybı konularında çok titiz bir eğitimden geçmeleri gerekmektedir. Bu alanda hava trafik kontrolörlerinin edinmesi gereken uluslararası sertifikasyon FEAST (First European ATCO Selection Test - Avrupa Hava Trafik Kontrolörleri Seçme Testi) paketidir. Bu pakette; sözel algılama, reaksiyon zamanı, talimatları takip ve yeniden düzenleme, planlama kabiliyeti, işbirliği, kuralları uygulama ve öğrenme, hız ve dikkat testi, hafıza kapasitesi, anlık reaksiyon, üç boyutlu düşünme, sayısal ve şekilsel algılama, problem çözme, ortadan kaldırma, sonuçlarına karşı direnç alanlarında zamana karşı yarış, raporlama, notamlar, hava koridorları, hava sektörleri konusunda eğitimler alınır. Risk analizlerinin yapılması güvenlik ve emniyet araştırmaları açısından önemlidir. Bu konuya benzer olarak yer trafik alanında Eren ve arkadaşlarının yaptığı bir çalışmada yol geometrisi tabanlı risk tahmin modeli çıkarılmıştır [37]. Benzer yaklaşımlar hava trafik konularına da uygulanabilir.

\subsubsection{HTY'de hukuk ve politika araştırmaları}

HTY'de hukuk ve politika araştırmaları; havacılık hukuku, ulusal ve uluslararası anlaşmalar, prosedürler standartlar, havacılık politikaları, otoriteler ve kurumsallaşma alanları olarak sınıflandırılabilir. Havacılık politikaları alanları içinde Sivil Havacılık Genel Merkezi (SHGM) mevzuatı, hava ve yer trafik riskleri, insan faktörü, risk yönetimi, uluslararası mevzuatlar, uçuş izinleri, lisans anlaşmaları vb. konular yer almaktadır. Bu 
alandaki çalışmalar ulusal ve uluslararası birçok havacılık politikalarına hâkimiyeti gerektirmektedir. Ayrıca hava sahası kapasitesi ve kullanımına ilişkin olarak ilgili kurum ve kuruluşlarla koordineli bir şekilde NOTAM ve Havacılık Bilgi Yayını yayımlamak veya yayımlanmasını sağlamak, bunun dışında kalan hususlarda servis sağlayıcı kuruluşlar tarafından NOTAM ve Havacılık Bilgi Yayını yayımlanmasına ilişkin usul ve esasları belirlemek, gerekli düzenlemeleri yapmak ve tedbirleri almak gereklidir. Havacılık otoritelerince; yasak, tehditli ve tehlikeli sahaların belirlenmesi aşamasında askeri ve sivil kuruluşların görüşlerini alarak gerekli işlemleri başlatmak, sivil hava araçlarının kamu ve uçuş emniyeti ile hava seyrüsefer güvenliği bakımından uyması gereken düzenlemeleri yapmak, denetlemek hukuksal bir konudur. Ayrıca hava trafik yönetim hizmetleriyle ilgili önlemler almak ve ilgili personelin lisanslandırılma esaslarını belirlemek, takibini yapmak, yenilemek ve iptal etmek, HTY ile ilgili ulusal ve uluslararası kurum, kuruluş ve teşkilatlarla çalışmalar yapmak, gerektiğinde mevzuat düzenlemeleri ile uygulamaların yapılmasını sağlamak ve takip etmek gerekmektedir. Türkiye hava sahasını ve havalimanlarını kullanarak gerçekleştirilecek uçuşlar, 2920 sayılı Türk Sivil Havacılık Kanunu başta olmak üzere ilgili mevzuat ve Havacılık Bilgi Yayını (AIP) prosedürleri, uçuş izin başvuruları, tarafından hava seyrüsefer alanında geliştirilen standart ve tavsiye edilen uygulamalar (SARPs) ile bunların dünya çapında uygulanması vb. araştırmalar ve uygulamalar bu alandaki çalışmaların içerisindedir. Havacılık hukuku ve politikaları disiplinler arası çalışmalara açık bir alan olup her geçen gün gelişmektedir.

\subsubsection{HTY'de yeni teknolojilerin araştırmaları}

HTY'de yeni teknolojilerin araştırmaları; veri tabanları, otomasyon, otonom veya insansız uzaktan kontrollü hava araçları için trafik yönetimi, gelecekteki iş modelleri ve sosyal medya kullanımı konularındaki araştırmalar olarak sınıflandırılabilir. Günümüzün yoğun hava ulaşım sistemleri sadece uçuş emniyetini değil daha fazla kapasite ve verimlilik ihtiyacını da beraberinde getirmektedir. Kapasite artarken daha etkin operasyonların gerçekleştirilmesinin yeni haberleşme, navigasyon, takip ve HTY teknolojileri sayesinde yapılabilmesi beklenmektedir. Amerika Birleşik Devletleri'ndeki NextGen, Avrupa'daki SESAR ve Japonya'daki CARATS gibi pek çok araştırma programı bu anlamda yenilikler sunmaya devam etmektedir. İnsansız hava araçlarının (İHA) kullanımı gün geçtikçe artmaktadır. İHA'ların gökyüzündeki artışı hava trafik gereksinimini doğurmaktadır. İnsansız hava trafik yönetim sistemi (IHHA-HTK) özellikle şehir alanında kritik bir öneme sahiptir. Bir kırım esnasında ciddi can ve mal kaybı ortaya çıkabilir. Ayrıca bilgisayar destekli bir sistem olarak İHA hava trafik sistemleri siber vandalizm ve siber savaşlara açıktır. NASA'da yapılan bir çalışmada 2016 yılında İHA'lar için örnek bir HTY konsepti geliştirilmiştir. Çalışmada düşük irtifalı küçük İHA'ların şehirlerde kullanımında trafik yönetiminin nasıl olabileceği tartışılmaktadır. Esneklik ve risk esaslı iki yaklaşım benimsenerek İHA-HTK konsepti tasarlanmıştır [38]. Otomasyon kullanımının arttırılması yanında haberleşme, seyrüsefer ve izleme alanında yeni teknolojilerin kullanılması, HTY'nin gelişiminde önemli rol oynayacaktır. Otomasyonun sadece hava trafik kontrol kapasitesi artışını sağlaması değil, aynı zamanda emniyet ve verimi arttırarak, personel, bakım maliyetleri ve kontrolör iş yükünü azaltması beklenmektedir [4]. HTY'de otomasyona geçiş günümüz geleneksel hava taşımacılığının yanında İHA'ların da sisteme dahil edilmesi ile daha önemli hale gelmiştir. Sivil küçük İHA'ların kullanımının yakın gelecekte artış göstermesi ile mevcut hava trafik yoğunluğunun çok yüksek seviyelere çıkacağı düşünülmektedir. Bu yoğunluk artışı otomasyonun gereksinimini arttırmaktadır. 2019 yılı yaklaşımında otomatik HTK sistemlerinde derin öğrenme yaklaşımlı bir sistem geliştirilmekte ve testleri devam etmektedir [39]. Son yıllarda yolculuk modelleri değişmektedir. Mobil ağların yoğun kullanımı ile online yaşam tarzları gündemdedir. Yeni nesil kuşak tatil için hava yolu ile seyahat etmek yerine vaktinin çoğunu sosyal medya kullanımı ile online ortamlarda geçirmektedir, bu konuda ciddi istatistiki veriler mevcuttur. Yaşam tarzlarındaki bu değişikliklerin hava trafiğine etkisi olabilir ve HTY alanında dikkate alınabilir. HTY'de gelecekte yeni iş modelleri oluşması muhtemeldir. Endüstriyel perspektiften bakılırsa iş modellerinin geliştirilmesi önemlidir. Uçak sistemlerinde geliştirilme yapılması büyük şirketler ölçeğinde yapılabilecek çalışmalar olduğundan bu kısımda detaylı açıklanmayacaktır. Bunun yerine havacılıktaki yönelim olan insansız hava taşımacılığında yapılabilecek yeniliklerden ve yeni iş modellerinden bahsedilecektir. Özellikle enerji sistemleri üzerinde yapılabilecek geliştirmeler ile yeni teknolojileri hayatımıza katmak için kurulmuş işletmeler yeni bir iş kolu olarak düşünülebilir. Yeni teknoloji batarya sistemlerini üretebilecek işletmeler, verimli enerji depolama sistemleri geliştirmeleri ve üretimleri bu alanda yeni iş modellerindendir. Batarya şarj istasyonları tasarımı, kurulumu, bakımı ve şarj istasyonlarındaki hava trafiğinin yönetimi yeni bir iş kolu olabilir. Ayrıca araştırmacıların bakış açısı ile HTY uzmanlarının analitik uygulamalarını kullanarak yeni tasarımlar yapabilmesi önemlidir. Hava taksi adı ile geçen insansız hava taşımacılığının yakın gelecekte şehir yaşamına entegre edilmesine çalışılmaktadır [40,41]. İnsansız hava taşımacılığı için kurulması gereken yeni sistemde yerel trafik kontrol üniteleri tasarlanabilir ve hava taksi iniş kalkışlarında kontrolör desteğine ihtiyaç doğabilir. Bu da kontrolör ihtiyacında ciddi bir artış doğurabilecektir. 
Her ne kadar HTK'da otomasyon yaklaşımı benimsenmeye çalışılsa da kontrolör desteğine ihtiyaç devam edecektir. Otomasyon sistemlerinin geliştirilmesi ya da sistem iyileştirilmesi için gerekli iş gücü de yeni bir iş kolu olarak düşünülebilir.

\section{Tartışma}

HTY araştırma konularının sınıflandırılmasında birçok alt başlık mevcuttur. Tüm bu alt başlıklara ve özel araştırma alanları dikkate alındığında HTY alanının ne denli geniş olduğu görülür. Her bir konu farklı disiplinler ile işbirliği yapılabilecek seviyede araştırma problemleri içerir.

Şekil 4'te hava trafik yönetimi araştırma alanları sınıflandırması verilmişsir. Bu yayında HTY alanındaki araştırma alanları Operasyonel Sistem araştırmaları, Haberleşme ve Seyrüsefer Sistemi araştırmaları, Performans ve Verimlilik araştırmaları, Veri Analizi araştırmaları, Güvenlik ve Emniyet araştırmaları, Hava Hukuku ve Politika araştırmaları ve Yeni Teknolojiler araştırma alanları olarak ana başlıklarına ayrılmıştır. Her alan bazı güncel örnekler ile detaylandırılmıştır. Tüm bu sınıflandırma çalışmalarına göre HTK araştırma alanlarına ne denli geniş perspektiften bakılması gerektiği görülebilir.

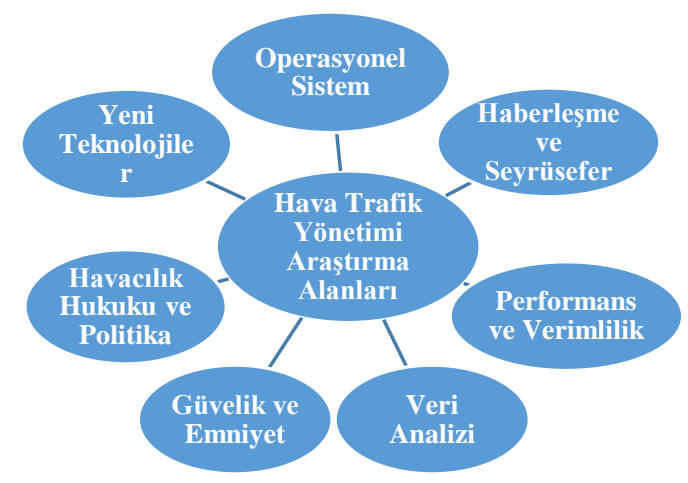

Şekil 4. Hava Trafik Yönetimi araştırma alanlarının sınıflandırılması

Hava yolu şirketleri açısından HTY konularında tüm dünyada eksiklikleri sürekli gündeme getirilen bir konu uçuş tarifelerinde yaşanan gecikmelerdir. Şekil 5 (a)'da ABD'de Ocak-Haziran 2019 tarihleri arasında gerçekleşen uçuş gecikmeleri istatistiği verilmiştir [42].
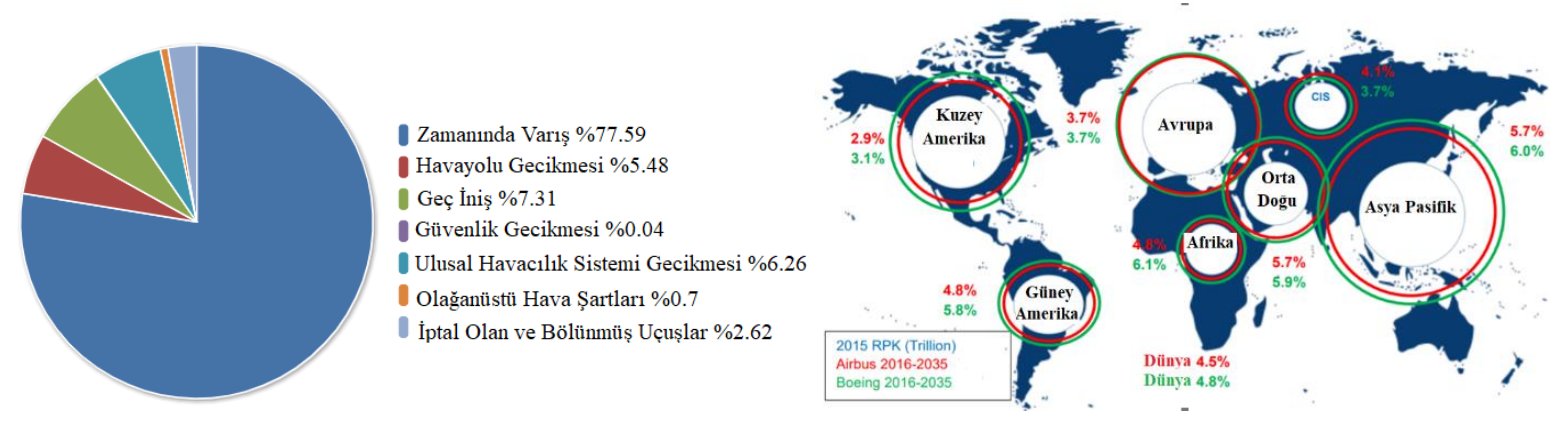

Şekil 5. (a) ABD uçuş gecikmeleri istatistiği (Ocak-Haziran 2019) [42], (b) Hava yolu şirketlerinin 20162035 aralığında öngördükleri hava trafik artışı haritası [43].

$\mathrm{Bu}$ istatistiğe göre yapılan uçuşların sadece \%77.59'u zamanında varış gerçekleştirebilmiştir [42]. Uçuş tarifelerindeki gecikmelerin ekonomik yansımaları çok büyüktür. Bu sebeple gecikmelerin sebepleri ve nasıl en aza indirilebileceği konusunda çalışmalar yapılmaktadır. Hava yolu araştırmacıları hava şartları sebebi haricindeki gecikmelerin hava trafik yönetim kaynaklı gecikmelerin bütünü olduğunu öne sürmektedir. HTY, hava trafik akış kontrol ve kapasite kontrol alanında yapılabilecek tüm akademik araştırmaların ve geliştirme çalışmalarının ekonomik yönden faydalar sağlayacağı düşünülmektedir. 
Hava yolu şirketlerinin 2016-2035 aralığında öngördükleri hava trafik artışı haritası Şekil 5 (b)'de verilmiştir. Buna göre 2035'e gelindiğinde hava trafiğindeki artışın bölgesel farklılıklarla birlikte \%3-6 arasında olacağı düşünülmektedir [43]. Dünyadaki hava alanları kapasitesinin, hava trafiğinde beklenen bu artış ile orantılı olmadığını gösteren araştırmalar vardır. HTY'de oluşacak bu kapasite problemi gelecek yıllarda yapılacak araştırmalarda önem kazanacaktır. Siyasi ve çevresel gündemler, çoğu gelişmiş ülkede yeni pistlerin kolay bir şekilde inşa edilemeyeceği ve mevcut altyapının maksimum potansiyelinde kullanılması gerektiği şeklinde fikirlerini ortaya koymaktadır. Tüm dünya bölgeleri, HTY altyapısını güncellemek, geliştirmek ve uyumlulaştırmak için kurulmuş programlar geliştirmeye devam etmektedir. SESAR (AB) ve NEXTGEN (ABD)'in Japonya'daki büyük CARATS programının desteğiyle birlikte, ICAO Blok yükseltme programının küresel HTY'yi modernize etmesine yönelik uzun vadeli programlar başlatılmıştır [43]. Ulusal HTY uygulamalarında küresel HTY teknolojilerinin takip edilmesi ve bu konulardaki eksikliklerin tespit edilip araștırmaların yapılması önemlidir.

Yayının son kısmında gelecekte HTY kavramının hangi yöne evrildiğine değinilmiş ve birkaç güncel örnek eklenmiştir. Özellikle otomasyon konusunun HTY açısından gelecekte son derece önem kazanacağı öngörülmektedir. HTY'de otomasyon seviyesinin ne olması gerektiği tartışmalara açıktır. Bu konuda tam otomasyonu savunan çalışmalar olmasına rağmen sayısal olarak en iyi performansın kontrolör ve otomatik sistem kombinasyonundan çıkacağını gösteren çalışmalar vardır [44,45]. Yayın içerisinde bahsedilmeyen fakat son aylarda gündeme gelen bir konu da Uzay Trafik Yönetimi (UTY) (Space Traffic Management) kavramıdır. UTY; uzay araçları ile etkinlik gösteren ülkelerin uzay ortamındaki işlemlerinin güvenliği, kararlılığ 1 ve sürdürülebilirliği için gereken planlama ve yönetim çalıșmaları olarak tanımlanabilir.

Uluslararası ve Ulusal Hukuk çerçevesinde HTY alanında birçok düzenlemeler ve yenilemeler gün geçtikçe daha kapsamlı yapılmaktadır ve bu konudaki gereksinimler varlığını sürdürecektir. Hukuk veya politika disiplinlerinden araştırmacılar HTY alanında disiplinler arası araştırmalar yapabileceklerdir.

\section{Sonuçlar}

Bu çalışmada dünyada Hava Trafik Yönetimi (HTY) alanındaki mevcut araștırma alanları hakkında değerlendirmeler verilmiştir. HTY araştırma alanları sınıflandırılmıştır. Bu başlıklara ait güncel araştırma konu başlıklarından bahsedilmiştir. Bu yayında HTY araştırma konuları 7 ana alana ayrılmıştır. Bunlar; Operasyonel Sistemler; Haberleşme ve Seyrüsefer Sistemleri; Performans ve Verimlilik; Veri Analizleri, Güvenlik ve Emniyet; Havacılık Hukuku ve Politikaları ve HTY'de Yeni Teknolojiler başlıklarıdır. Bu sınıflandırma yapısının bu alanda çalışmak isteyen ulusal araştırmacılara bir ufuk açacağı düşünülmektedir. Son olarak gelecekteki olası HTY problemleri ve araştırmacıların desteğine ihtiyaç duyulabilecek alanlardan bahsedilmiştir. HTY araştırma alanlarının hangi yöne evrildiği farklı açılardan ele alınarak değerlendirilmiştir. Bir sonraki çalışmamızda geleceğin uçuş teknolojileri de hesaba katılarak Hava Trafik Kontrol alanında araştırma yapılması planlanmaktadır.

\section{Kaynaklar}

[1] https://www.icao.int/Meetings/STA10/Documents/Sta10_Wp007_en.pdf; erişim tarihi: 11.02.2020.

[2] https://www.eurocontrol.int/master-plan-architecture-and-monitoring; erişim tarihi: 11.02.2020.

[3] https://www.easa.europa.eu/easa-and-you/air-traffic-management/atmans-organisations-approvals-and-atco-trainingorganisations-approvals; erişim tarihi: 11.02.2020.

[4] Cavcar M. Havacılığa Giriș. Eskișehir. Anadolu Üniversitesi Yayınları, 2015.

[5] https://www.icao.int/annual-report-2017/Pages/the-world-of-air-transport-in-2017.aspx; erişim tarihi: 11.02.2020.

[6] https://utm.arc.nasa.gov/index.shtml; erişim tarihi: 11.02.2020.

[7] https://bilgem.tubitak.gov.tr/tr/urunler/sivil-havacilik-cozumleri-0; erişim tarihi: 11.02.2020.

[8] Isaac A. Human error in European ATM: HERA project. Reliab.Eng.\&System Safety 2016; 75(2): 257-272.

[9] Conde RMM, Balakrishnan H. Trajectory clustering and classification for characterization of air traffic flows. 16thAIAA Aviation Tech., Integration, Operations Conference; 13-17 June 2016; Washington, USA: pp.3760.

[10] Bosson CS, Nikoleris T. Supervised learning applied to air traffic trajectory classification. AIAA Information SystemsAIAA conference; 8-12 January 2018; Kissimmee, Florida: pp.1637.

[11] Liu PCB, Hansen M, Mukherjee A. Scenario-based air traffic flow management: From theory to practice. Transportation Research Part B: Methodological 2008; 42: 685-702.

[12] Christien R, Benkouar A, Chaboud T, Loubieres P. Air traffic complexity indicators \& ATC sectors classification. The 21st Digital Avionics Systems Conference; 27-31 Oct. 2002; Irvine, CA, USA: IEEE. pp. 2D3-2D3.

[13] Austrian EM, Berry KA, Sawyer MW, DeHaas A. Planning for the Future: Human Factors in NextGen Air Traffic Management. 18th International Symposium on Aviation Psychology; 4-7 May 2015; Dayton, Ohio, USA: pp. 294. 
[14] Cook A, Rivas D. Complexity science in air traffic management. Routledge press, 2016.

[15] Cook A, Blom HA, Lillo F, Mantegna RN, Micciche S, Rivas D, Zanin M. Applying complexity science to air traffic management. Journal of Air Transport Management 2015; 42: 149-158.

[16] Corver S, Grote G. Uncertainty management in enroute air traffic control: a field study exploring controller strategies and requirements for automation. Cognition, Technology \& Work 2016; 18(3): 541-565.

[17] Sampigethaya K, Kopardekar P, Davis J. Cyber security of unmanned aircraft system traffic management (UTM). Integrated Communications, Navigation, Surveillance Conf. (ICNS); 10-12 April 2018; Herndon, VA, USA: IEEE pp. $1 \mathrm{C} 1-1$.

[18] Ören A, Koçyiğit Y. İnsansız hava araçları iniş sıralamasının bulanık mantık modellemesi. CBÜ Fen Bil. Dergi 2016; 12(1): pp. 55-66.

[19] Özbek E. Hava Trafik yönetiminde koordinasyon: Türkiye hava sahasının esnek kullanımı konseptinin koordinasyon süreçlerinin betimlenmesi, MSc Tez, Anadolu Üniversitesi, Eskişehir, Türkiye, 2015.

[20] Dönmez K. Türk hava sahasında meydana gelen ölümcül uçak kazalarına insan faktörleri analiz ve sınıflandırma sisteminin (HFACS) Uygulanmas1. The Journal Of Academic Social Science Studies 2017; 6(59): 229-253.

[21] Paşaoğlu C. İnsansız hava araçlarının ulusal hava sahalarına entegrasyonu ve yeni hava trafik yönetimi konsepti için otomatik HTK modellemesi ve uçuş yönetim sistemi geliştirilmesi, Doktora Tezi, Gazi Üniversitesi, Ankara, Türkiye, 2016.

[22] Aydoğan E. Hava trafik akış ve kapasite yönetiminde saha kontrol için toplama noktası yaklaşımı, MSc Tez, Anadolu Üniversitesi, Eskişehir, Türkiye, 2015.

[23] Wu CL, Caves RE. Research review of air traffic management. Transport Reviews 2002; 22(1): 115-132.

[24] Bianco L, Bielli M. Air traffic management: Optimization models and algorithms. Journal of Advanced Transportation 1992; 26(2): 131-167.

[25]Cavcar A. Hava trafik akış planlaması için karar destek sistemi ve Türkiye için öneriler. http://www.imo.org.tr/resimler/ekutuphane/pdf/11666.pdf; erişim tarihi: 11.02.2020.

[26] Kopardekar P, Magyarits S. Dynamic density: measuring and predicting sector complexity. In Proceedings. The 21st Digital Avionics Systems Conference; 27-31 Oct. 2002; Irvine, CA, USA: IEEE. pp. 2C4-2C4.

[27] Laudeman IV, Shelden SG, Branstrom R, Brasil CL. Dynamic Density: An Air Traffic Management Metric 1998; No. NAS 1.15: 112226, NASA/TM-

[28] Hafidi M, Benaddy M, Krit SD. Review of Optimization and Automation of Air Traffic Control Systems. In Proceedings of the Fourth International Conference on Engineering \& MIS; June, 2018; Istanbul, Turkey: pp. 10.

[29] Chertow MR. The IPAT Equation and Its Variants. J. Ind. Ecol. 2000; 4(4): 13-29.

[30] Özgür M. Taktik hava trafik akış ve kapasite yönetimi için bir optim. modeli, Tez, Anadolu Üniv., Eskişehir, TR, 2013.

[31] https://ssd.dhmi.gov.tr/Sayfalar/default.aspx; erişim tarihi: 11.02.2020.

[32] https://www.eurocontrol.int/communications-navigation-and-surveillance; erişim tarihi: 11.02.2020.

[33] https://www.skybrary.aero/index.php/Situational_Awareness; erişim tarihi: 11.02.2020.

[34] Dominguez C, Vidulich M, Vogel E, McMillan G. Situation awareness: Papers and annotated bibliography. Armstrong Laboratory, Human System Center 1994; ref. AL/CF-TR-1994-0085

[35] Celenk M, Eren H, Poyraz M. Prediction of driver head movement via Bayesian Learning and ARMA modeling. Intelligent Vehicles Symposium; 3-5 June 2009; Xi’an, Shaanxi, China: IEEE. pp. 542-547.

[36] Tunç İ. Emniyet yönetim sistemi uygulamalarının hava trafik kontrol hizmetlerine katkılarının analizi, Doktora Tezi, Anadolu Üniversitesi, Eskişehir, Türkiye, 2018.

[37] Karaduman O, Eren H, Kurum H, Celenk M. Road-geometry-based risk estimation model for horizontal curves. IEEE Transactions on Intelligent Transportation Systems 2016; 17(6): 1617-1627.

[38] Kopardekar P, Rios J, Prevot T, Johnson M, Jung J, Robinson JE. Unmanned aircraft system traffic management (UTM) concept of operations. 16th AIAA Aviation Technology, Integration, and Operations Conference; 13-17 June 2016; Washington, DC, USA: Vol.13.

[39] Brittain M, Wei P. Autonomous Air Traffic Controller: A Deep Multi-Agent Reinforcement Learning Approach. 36 th ICML Conference; June 14, 2019; Long Beach, CA, USA: arXiv preprint arXiv:1905.01303.

[40] Celik K, Eren H, UAV fuel preferences for future cities, 6th International Istanbul Smart Grids and Cities Congress and Fair ICSG; 25-26 April 2018; Istanbul, Turkey: pp. 151-154.

[41] Karaduman M, Çınar A, Eren H. UAV Traffic Patrolling via Road Detection and Tracking in Anonymous Aerial Video Frames, J. Intelligent Robotics Systems 2019; 95(2): 675-690.

[42] https://www.transtats.bts.gov/OT_Delay/ot_delaycause1.asp?type=1\&pn=1; erişim tarihi: 11.02.2020.

[43] https://ec.europa.eu/transport/sites/transport/files/2016_eu_air_transport_industry_analyses_report.pdf; erişim tarihi: 11.12.2020.

[44] Martin L, Bienert N, Claudatos L, Gujral V, Kraut J, Mercer J. Effects of task allocation on air traffic management humanautomation system performance, IEEE/AIAA 35th Digital Avionics Systems Conference DASC; 25-30 Sept 2016; Sacramento, CA, USA: pp. 1-8.

[45] Metzger U, Parasuraman R. Automation in Future Air Traffic Management: Effects of Decision Aid Reliability on Controller Performance and Mental Workload, Hum. Factors J. Hum. Factors Ergon. Soc 2005; 47(1): 35-49. 